\title{
Compatibility Test Research on Mine Cementitious Materials And Unclassified Tailings
}

\author{
Guoquan Hou ${ }^{1, a}$, Lijie Guo ${ }^{1, b}$, Chao Yang ${ }^{1, c}$ and Wenyuan $\mathrm{Xu}^{1, \mathrm{~d}}$ \\ 1.Beijing General Research Institute of Mining \& Metallurgy, Beijing 100160, China;

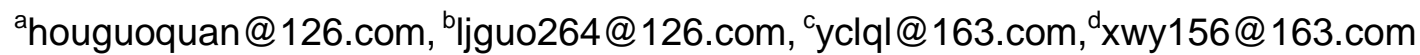

Keywords: Mine Fillings; Unclassified Tailings; Cementitious Materials; Uniaxial compressive strength.

Abstract: This paper does corresponding test research on new type Mine Cementitious Materials from basic performance, strength of cemented tailings backfill and influence factor, fluidity of filly slurry and other aspects of the binding material. It can be seen from the test results that mining cementation power can better apply to tailing cementing and filling of mine, all its indicators are superior to originally used cement, which provides basic data support for evaluating performance of mining filling and binding materials and its industrial application.

\section{Introduction}

As the material basis for national economic development, mineral resources has been widely developed and utilized, but for a long term, the extensive disorder, gopher has caused great damage and loss to mineral resources. In the course of mining, large number of goafs produced, the tailings left by mineral separation, have severely destroyed biological balance of the mine lot. Through mine's production, it is found that adopting local cement as binding material, unit consumption of cement is higher, which in turn result in higher filling cost. To save filling cost, suitable mining cementitious material of filling has been developed in view of features of whole tailings mine by mine.

This paper does corresponding test research on new type mining cementation power from basic performance, strength of cemented tailings backfill and influence factor, fluidity of filly slurry and other aspects of the binding material. It provides basic data support for evaluating performance of mining filling and binding materials and its industrial application.

\section{Basic parameters test of mine-fill}

\section{Chemical component of tailings}

Adopting ICP (Inductive Coupled Plasma Emission Spectrometer) to do semi quantitative spectral analysis to metallic element contained in the whole tailings, the main metallic element in whole tailings are A1, Fe.The analysis results are shown in Table 1. 
Table 1 ICP emission semi quantitative spectral analysis and test results of whole tailings

\begin{tabular}{cccc}
\hline Analysis item & Result[\%] & Analysis item & Result[\%] \\
\hline $\mathrm{Al}$ & 6.98 & $\mathrm{Li}$ & $<0.05$ \\
$\mathrm{As}$ & $<0.05$ & $\mathrm{Mg}$ & 0.34 \\
$\mathrm{Ba}$ & 0.057 & $\mathrm{Mn}$ & 0.11 \\
$\mathrm{Be}$ & $<0.05$ & $\mathrm{Ni}$ & $<0.05$ \\
$\mathrm{Bi}$ & $<0.05$ & $\mathrm{~Pb}$ & $<0.05$ \\
$\mathrm{Ca}$ & 0.75 & $\mathrm{Sb}$ & $<0.05$ \\
$\mathrm{Cd}$ & $<0.05$ & $\mathrm{Sn}$ & $<0.05$ \\
$\mathrm{Co}$ & $<0.05$ & $\mathrm{Sr}$ & $<0.05$ \\
$\mathrm{Cr}$ & $\mathrm{Ti}$ & 0.058 \\
$\mathrm{Cu}$ & $<0.05$ & $\mathrm{~V}$ & $<0.05$ \\
$\mathrm{Fe}$ & 2.05 & $\mathrm{Zn}$ & $<0.05$ \\
\hline
\end{tabular}

Quantitative chemical all-element analysis has been further conducted targeting the main metallic element and non-metal element.

Table 2 Quantitative analysis result of element

\begin{tabular}{cccccccc}
\hline Component & $\mathrm{SiO}_{2}$ & $\mathrm{Al}_{2} \mathrm{O}_{3}$ & $\mathrm{CaO}$ & $\mathrm{MgO}$ & $\mathrm{K}_{2} \mathrm{O}$ & $\mathrm{Na}_{2} \mathrm{O}$ & $\mathrm{TiO}_{2}$ \\
\hline Taste[\%] & 72.03 & 1.93 & 0.88 & 0.59 & 4.82 & 0.38 & 0.11 \\
\hline
\end{tabular}

It can be seen from the table2, main nonmetallic oxide in the tailings is $\mathrm{SiO}_{2}$, the content of which is $72.03 \%$; while content of other metallic element is lower.

\section{Physical parameters of tailings}

Do test on specific gravity, unit weight, and porosity of tailings according to soil test regulations, the result of which is shown in Table 3.

Table 3

Basic physical parameter table of tailings

\begin{tabular}{cccc}
\hline Name & Density $\left[\mathrm{g} / \mathrm{cm}^{3}\right]$ & Unit weight $\left[\mathrm{g} / \mathrm{cm}^{3}\right]$ & Porosity [\%] \\
\hline Whole tailings & 2.6 & 1.62 & 37.7 \\
\hline
\end{tabular}

\section{Grading analysis of tailings}

Graded composition of tailings, which can be seen in Table 4. Figure 1 is the curves of graded composition.

\begin{tabular}{clllllll} 
Table 4 & \multicolumn{6}{c}{ Particle Size Distribution and Content Table of Whole Tailin } \\
\hline $\begin{array}{l}\text { Grain } \\
\text { diameter } \\
{[\mu \mathrm{m}]}\end{array}$ & $\begin{array}{l}\text { minus } \\
\text { sieve } \\
\text { adding }\end{array}$ & $\begin{array}{l}\text { Grain } \\
\text { daiameter } \\
{[\mu \mathrm{m}]}\end{array}$ & $\begin{array}{l}\text { minus } \\
\text { sieve } \\
\text { adding } \\
\text { up[\%] }\end{array}$ & $\begin{array}{l}\text { Grain } \\
\text { diameter } \\
{[\mu \mathrm{m}]}\end{array}$ & $\begin{array}{l}\text { minus } \\
\text { sieve } \\
\text { adding } \\
\text { up }(\%)\end{array}$ & $\begin{array}{l}\text { Grain } \\
\text { diameter } \\
{[\mu \mathrm{m}]}\end{array}$ & $\begin{array}{l}\text { minus } \\
\text { sieve } \\
\text { adding } \\
\text { up }(\%)\end{array}$ \\
\hline 0.4 & 0 & 10 & 21.06 & 37 & 46.54 & 90 & 67.4 \\
1 & 1.61 & 15 & 28.55 & 40 & 48.2 & 100 & 70.23 \\
2 & 3.87 & 20 & 34.12 & 50 & 53.1 & 150 & 81.65 \\
4 & 8.5 & 25 & 38.53 & 60 & 57.29 & 200 & 89.46 \\
6 & 13.11 & 30 & 42.2 & 70 & 60.99 & 400 & 99.88 \\
8 & 17.33 & 35 & 45.38 & 80 & 64.34 & 500 & 100 \\
\hline
\end{tabular}




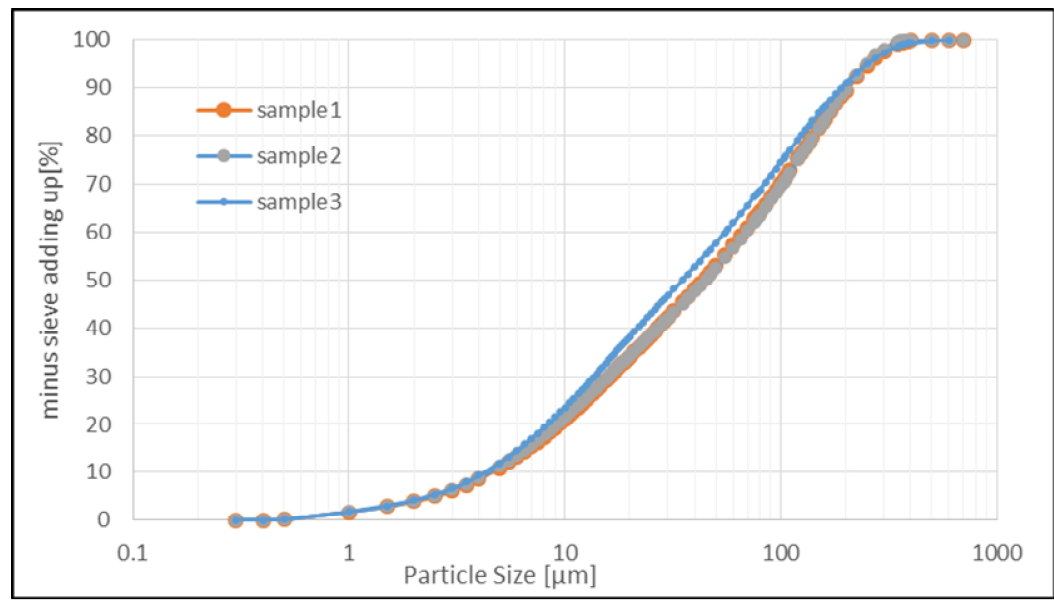

Fig. 1 Size distribution curve of whole tailings

Whole tailings $\mathrm{d} 10$ is $4.637 \mu \mathrm{m}$, d50 is $43.473 \mu \mathrm{m}$, and $\mathrm{d} 90$ is $204.345 \mu \mathrm{m}$. Graded composition nonuniform coefficient of whole tailings is 14.45 respectively.

\section{Basic property test of Cementitious Materials}

\section{Density of Cementitious Materials}

The test is done by reference to Standard Test Method for Cement Density GB/T208-2014, and Le pycnometer is adopted to test proportion of cementation powder.

Table 5 Test of density of Cementitious Materials

\begin{tabular}{cccccc}
\hline NO. & $\begin{array}{c}\text { Specimen quality } \\
{[\mathrm{g}]}\end{array}$ & $\mathrm{V}_{1}[\mathrm{~mL}]$ & $\mathrm{V}_{2}[\mathrm{~mL}]$ & $\begin{array}{c}\text { Specimen density } \\
{\left[\mathrm{g} / \mathrm{cm}^{3}\right]}\end{array}$ & $\begin{array}{c}\text { Average density } \\
{\left[\mathrm{g} / \mathrm{cm}^{3}\right]}\end{array}$ \\
1 & 61.362 & 0.7 & 23 & 2.752 & 2.759 \\
2 & 60.88 & 0.9 & 22.9 & 2.767 & \\
\hline
\end{tabular}

By test, tolerance of the two parallel tests is within 0.02, so density of the Cementitious Materials is determined as $2.759 \mathrm{~g} / \mathrm{cm}^{3}$.

\section{Quality inspection of cementation powder}

Sample inspection were conducted to binding materials produced by the mine at different phases, GB175-2007 cement test standard is adopted to do basic property test of mining binding materials. The test results are shown in Table 5.

It is observed from the test result that, except initial and final setting time, $28 \mathrm{~d}$ rupture strength and compressive strength of the cementation powder all have reached the compound portland cement standard.

Table 6 Cementitious Materials test analysis result

\begin{tabular}{ccccc}
\hline Sample & $\begin{array}{c}\text { Initial setting } \\
\text { time } \\
{[\mathrm{min}]}\end{array}$ & $\begin{array}{c}\text { Final setting } \\
\text { time } \\
{[\mathrm{min}]}\end{array}$ & $\begin{array}{c}\text { 28d rupture } \\
\text { strength } \\
{[\mathrm{MPa}]}\end{array}$ & $\begin{array}{c}28 \mathrm{~d} \text { compressive } \\
\text { strength } \\
{[\mathrm{MPa}]}\end{array}$ \\
\hline $\begin{array}{c}\text { Cementitious } \\
425\end{array}$ & 535 & 4.2 & 17.5 \\
32.5 level cement standard & $\geqslant 45$ & $\leq 600$ & $\geqslant 5.5$ & $\geqslant 32.5$ \\
\hline
\end{tabular}

\section{Strength characteristics of cemented fill of tailings.}

\section{Strength of filling mass influence factor analysis}

\section{1) Cement-sand ratio}

The influence of cement-sand ratio on strength of filling mass increases mainly along with addition of binding materials, its hydration reaction rate is fast, and extent of hydration reaction and product increases, at the same time, most notably is that it has improved the compactness of internal 
structure of fillings, thereby strength increases by macroscopic view ${ }^{[1]}$. Through SEM Micro-Structure Analysis of filling sclerotium with different cement-sand ratio, the Figure 2 can reflect this phenomenon obviously.

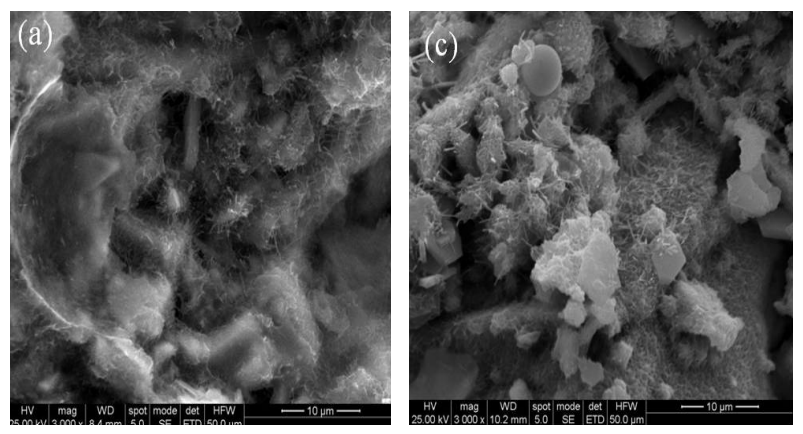

(a-cement-sand ratio 1:4; c-cement-sand ratio 1:8)

\section{Fig. 2 Internal structure of fillings with different cement-sand ratio}

\section{2) Concentration}

The influence of concentration of filling slurry on strength of fillings are mainly manifested along with the increase of filling slurry concentration, unit consumption of binding material within unit volume increases, meanwhile, the water yield involved in the reaction decreases ${ }^{[2]}$. Thereby, it allows the hydration reaction rate and extent of hydration reaction increases, further showing increase of quantity of gum materials in the filling, at the same time, the internal structure becomes more compact thereby manifested as increase of strength on macroscopic level. Through SEM Micro-Structure Analysis of filling sclerotium with different concentration, the Figure 3 can reflect this phenomenon obviously.
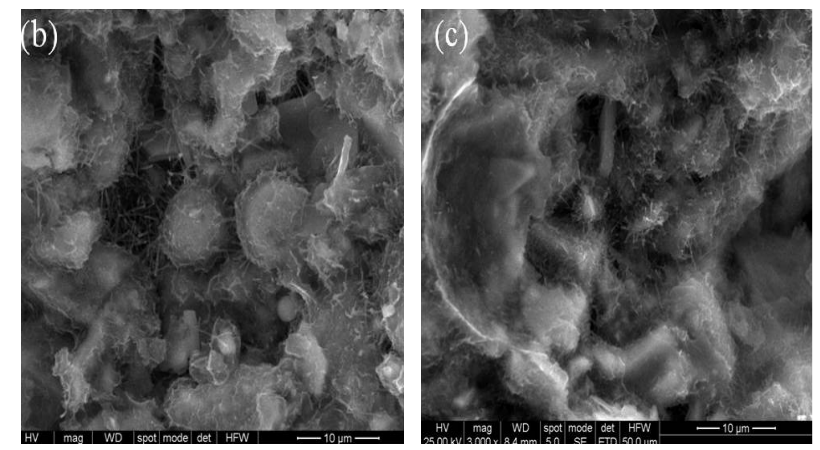

(a-Concentration 68\%; c-Concentration 70\%)

\section{3) Curing period}

Fig. 3 Internal structure of fillings of different concentrations

Influence of curing period of fillings on its strength is shown mainly in constant increase of hydration extent and products of binding materials along with increase of curing period, and internal structure becomes constantly compact. Thus, it is manifested in constant increase of filling strength, generally the curing period of filling is 28 days, its strength can reach $80 \%$ or so of final strength of the fillings, and after 60 days, it can reach over $90 \%$ of final strength.

\section{4) Curing way}

Curing way of filling is to simulate the influence of different environmental conditions on strength of fillings. It mainly includes water curing, sealed curing, concrete standard curing and air bare maintenance ${ }^{[3]}$. Thereinto, mining filling binding materials are liable to carbonize in the air, thus lead to reduction of strength in later period, affecting stability of the filling. 


\section{Comparative trial of binding materials}

If testing all indicators of the mining cementation powder by cement standard except initial and final setting time, the strength index does not meet standard of 32.5 level ordinary Portland cement, but test is still needed to know whether the filling prepared by whole tailings of the mine has corresponding strength advantage or not. Therefore, we did comparative test to two types of binding materials, the 28-day test results of standard curing period is shown in Table 7. Figure 4 is the comparison chart of filling strength of different binding materials.

Table 7 Test result of strength of fillings with different binding materials Unit[MPa]

\begin{tabular}{cccccccc}
\hline \multirow{2}{*}{$\begin{array}{c}\text { Type of binding } \\
\text { materials }\end{array}$} & $\begin{array}{c}\text { Density of } \\
\text { slurry[\%] }\end{array}$ & 4 & 6 & 8 & Cement-sand ratio & 10 & 12 \\
\cline { 3 - 7 } & 68 & 3.505 & 1.726 & 1.009 & 0.619 & 0.470 \\
cement & 70 & 3.505 & 1.726 & 1.009 & 0.619 & 0.470 & 0.917 \\
& 72 & 3.742 & 2.137 & 1.588 & 1.08 & 0.79 \\
Cementation & 68 & 5.34 & 3.06 & 1.75 & 2.06 & 0.98 \\
powder & 70 & 6.49 & 3.32 & 3.24 & 1.91 & 1.28 \\
\hline
\end{tabular}

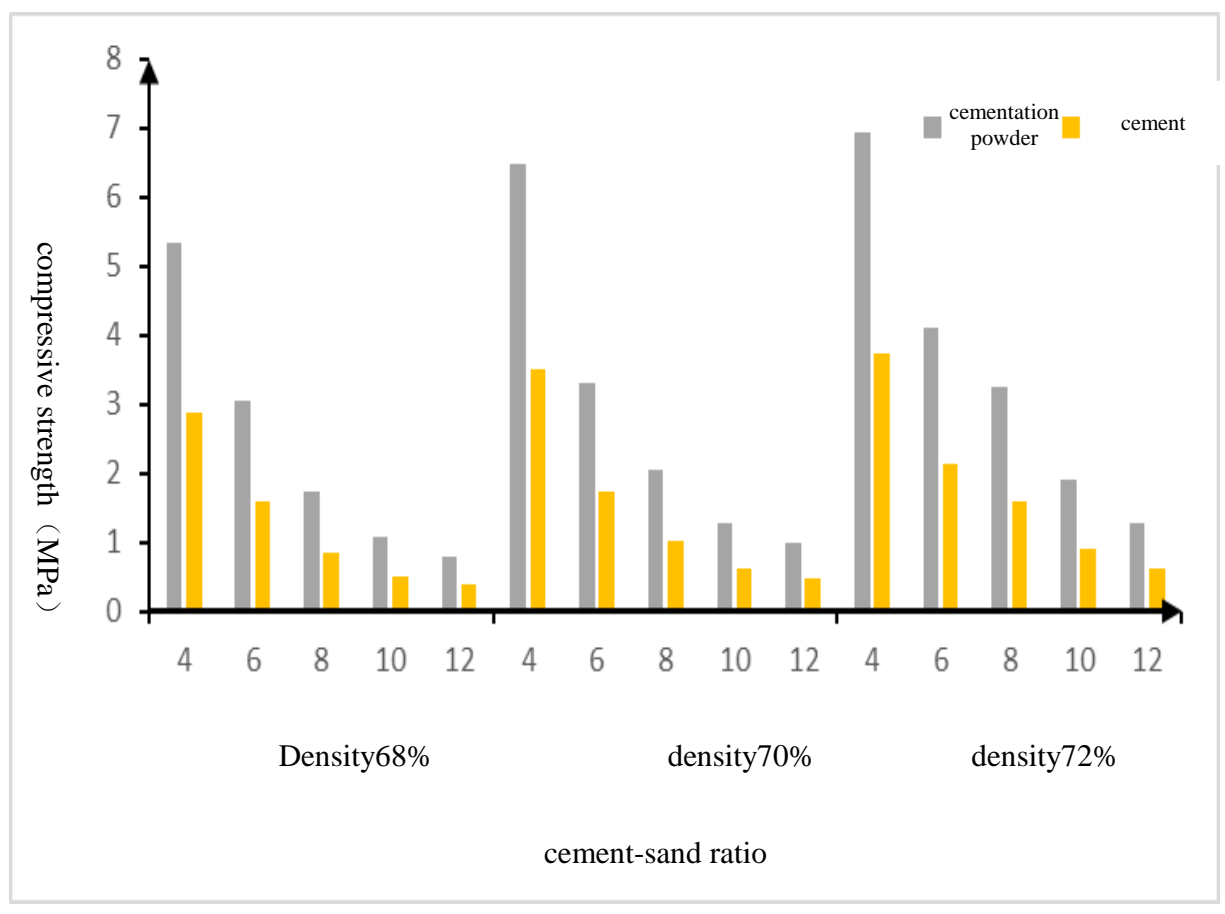

Fig.4 Comparative diagram of strength of different binding materials

According to comparative test results of filling strength of different binding materials (As shown in fig.4), adopting cementation powder as binding material, under the same concentration and cement-sand ratio, its strengths are all above strength of cement and tailings filling. Combined with the basic test results of mining filling binding materials, its matching with the mine tailing is superior to cement.

\section{Strength increase and carbonization mechanism of filling mass}

Comparing with cement, mining cementitious material of filling has advantages of rapid hardening, early strength, and high water consolidation; but its greatest defect lies in the fact that it is liable to carbonize in the air, which causes strength lowering at later phases. The growth and carbonization mechanism of the strength of such filling: at earlier stage, the filling slurry has large quantity of water, in which $1 \mathrm{AFt}$ molecule can bond to 32 hydrones, therefore, the hydration 
reaction rate of $\mathrm{AFt}$ is faster than $\mathrm{C}-\mathrm{S}-\mathrm{H}$ gel, thereby binding materials can do sufficient hydration reaction $^{[5]}$. In addition, at initial stage, it mainly depends on hydration reaction to create large number of AFt, to support early strength of the whole fillings, this is also the reason for such materials to have rapid hardening, early strength, and high water consolidation. While along with the end of AFt hydration reaction, large quantity of C-S-H gel is generated, which gradually become the main gel material supporting filling strength. At this moment, along with gradual decrease of water in the fillings, the surface layer of filling exposed in the air begins to carbonize, that is the AFt begins to lose its 32 crystal water, then surface of the fillings will pulverize, and develop from the surface to inside, and finally to the depth, which is the main reason resulting in reduced strength. Therefore, at the growth stage of fillings, appropriate separation of its surface layer with the air will achieve ideal filling strength.

\section{Fluidity of filly slurry}

\section{Diffusance test}

Fluidity of filly slurry is a comprehensive indicator to judge if it can realize gravity transportation and the maximum transportation density. Adaptation of mining filling binding material is also manifested in whether it has good fluidity or not, thus determines the conveying density meeting request of gravity feed. The paper adopts diffusance comprehensive evaluation to judge its fluidity of the slurry. Figure 5 is the test photo of slurry of different concentrations, and table 6 is the final test result.

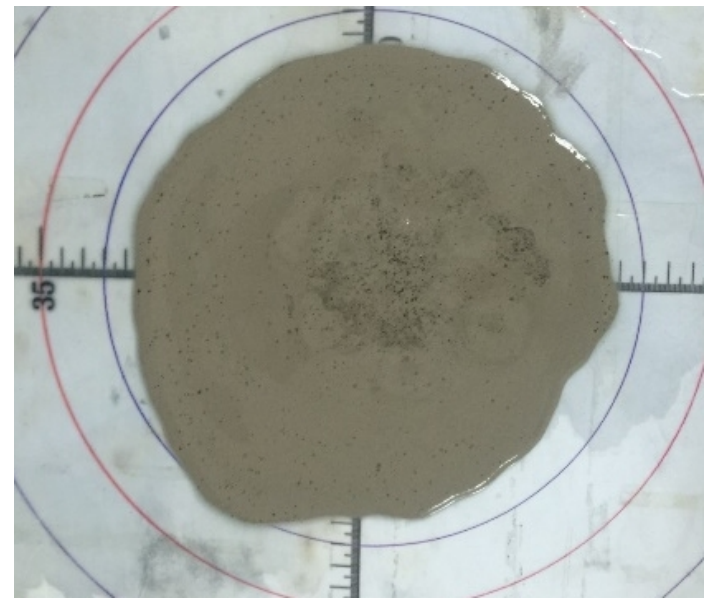

a) Concentration $68 \%$, cement-sand ratio $1: 4$

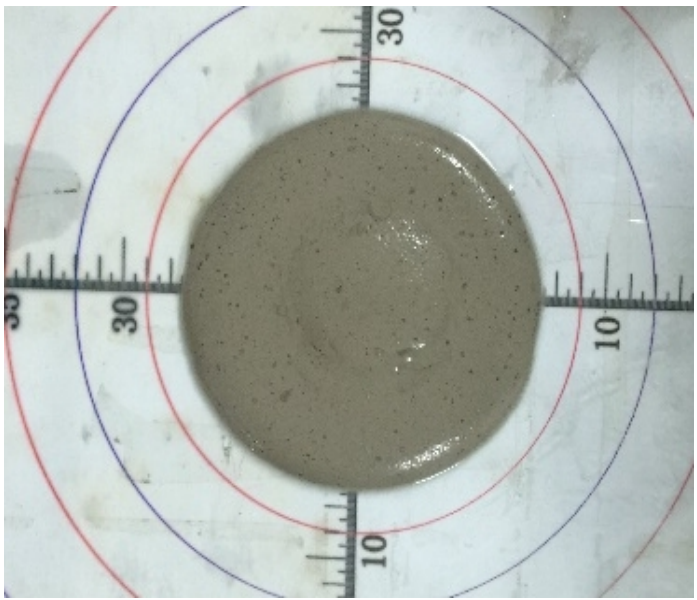

b) Concentration $72 \%$, cement-sand ratio $1: 4$

\section{Fig.5 Diffusance test of slurry of different concentration}

It is seen from the diffusance test result, that under certain cement-sand ratio of the filling material, the diffusance of the filling slurry will decrease along with increase of density, that is, along with the increase of concentration of filling slurry, its diffusance is poorer. From the test result, its diffusance is good under the $70 \%$ of concentration of filling slurry, while gravity feed turns difficult under $72 \%$.

Table 8 Data table of diffusance test of slurry Unit $[\mathrm{cm}]$

\begin{tabular}{cccccc}
\hline \multirow{2}{*}{ Concentration[\%] } & \multicolumn{3}{c}{ Cement-sand ratio } & $1: 10$ & $1: 12$ \\
\cline { 2 - 6 } & $1: 4$ & $1: 6$ & 22 & 20.5 & 19.8 \\
68 & 22.5 & 24.5 & 19 & 18.5 & 18.5 \\
70 & 20 & 19.5 & 14.5 & 13.5 & 14.5 \\
\hline
\end{tabular}




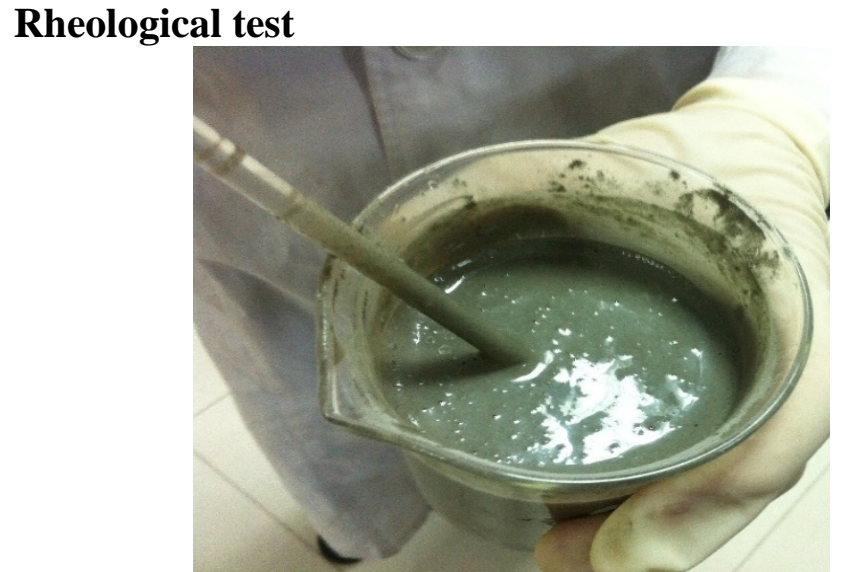

(a) Specimen allocation

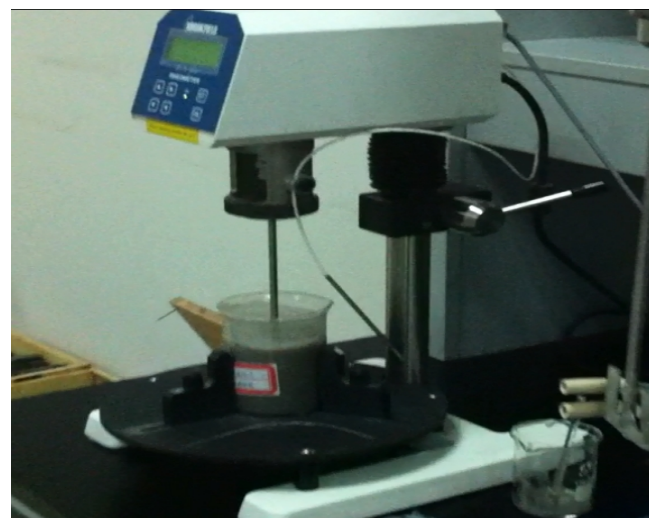

(d) Test process

Fig. 6 Process of rheological test

The test adopts the RST-SST type soft solid rheometer of American Brookfield Company to test the yield stress and coefficient of viscosity of the slurry. The test process is shown in fig.6, results are shown in Table 7.

Table 9 Flow curve fitting result of whole tailings filling slurry

\begin{tabular}{|c|c|c|c|c|c|c|}
\hline Concentration & Cement-sand ratio & Fitted equation & $\begin{array}{l}\text { Type of } \\
\text { model }\end{array}$ & Stability index & Yield stress[ $\mathrm{Pa}]$ & $\begin{array}{l}\text { Coefficient of } \\
\text { viscosity[ } \mathrm{Pa} \bullet \mathrm{s}]\end{array}$ \\
\hline \multirow{5}{*}{$68 \%$} & $1: 4$ & $y=0.1725 x+13.21$ & Bingham & $\mathrm{R}^{2}=0.9876$ & 13.21 & 0.1725 \\
\hline & $1: 6$ & $y=0.1571 x+13.655$ & Bingham & $\mathrm{R}^{2}=0.9831$ & 13.655 & 0.1571 \\
\hline & $1: 8$ & $y=0.2212 x+12.172$ & Bingham & $\mathrm{R}^{2}=0.9835$ & 12.172 & 0.2212 \\
\hline & $1: 10$ & $y=0.1972 x+11.423$ & Bingham & $\mathrm{R}^{2}=0.9881$ & 11.423 & 0.1972 \\
\hline & $1: 12$ & $y=0.1484 x+16.804$ & Bingham & $\mathrm{R}^{2}=0.9807$ & 16.804 & 0.1484 \\
\hline \multirow{5}{*}{$70 \%$} & $1: 4$ & $y=0.1823 x+26.651$ & Bingham & $\mathrm{R}^{2}=0.9887$ & 26.651 & 0.1823 \\
\hline & $1: 6$ & $y=0.2386 x+22.79$ & Bingham & $\mathrm{R}^{2}=0.986$ & 22.79 & 0.2386 \\
\hline & $1: 8$ & $y=0.1981 x+30.453$ & Bingham & $\mathrm{R}^{2}=0.9804$ & 30.453 & 0.1981 \\
\hline & $1: 10$ & $y=0.1505 x+33.619$ & Bingham & $\mathrm{R}^{2}=0.9275$ & 33.619 & 0.1505 \\
\hline & $1: 12$ & $y=0.1615 x+28.215$ & Bingham & $\mathrm{R}^{2}=0.97$ & 28.215 & 0.1615 \\
\hline \multirow{5}{*}{$72 \%$} & $1: 4$ & $y=0.1747 x+58.949$ & Bingham & $\mathrm{R}^{2}=0.9382$ & 58.949 & 0.1747 \\
\hline & $1: 6$ & $y=0.1629 x+65.566$ & Bingham & $\mathrm{R}^{2}=0.9604$ & 65.566 & 0.1629 \\
\hline & $1: 8$ & $y=0.0554 x+64.296$ & Bingham & $\mathrm{R}^{2}=0.8296$ & 64.296 & 0.0554 \\
\hline & $1: 10$ & $y=0.1013 x+63.081$ & Bingham & $\mathrm{R}^{2}=0.7835$ & 63.081 & 0.1013 \\
\hline & $1: 12$ & $y=0.0314 x+57.101$ & Bingham & $\mathrm{R}^{2}=0.7084$ & 57.101 & 0.0314 \\
\hline
\end{tabular}

Through fluid matching as per Bingham to filling slurry, it is found that, matching stability index is close to 1, which means it is suitable for Bingham fluid model. It is observed from matching result and rheological behavior curve, under the same cement-sand ratio, along with increase of slurry concentration, the yield stress $\left(\tau_{0}\right)$ increases, concentration rises from $70 \%$ to $72 \%$, and yield stress nearly doubles. This is because along with increase of concentration, first catch between particles of the slurry increases, force of friction inside the slurry magnifies, resulting in increase of yield stress. The yield $\operatorname{stress}\left(\tau_{0}\right)$ is generated by adhesive force and force of friction between particles within the slurry, which is the maximum stress hindering plastic deformation of the slurry. Thus, the denser the slurry, the poorer its fluidity. The rheological behavior curve of filling slurry of the same concentration and different cement-sand ratio see figure 7 . 

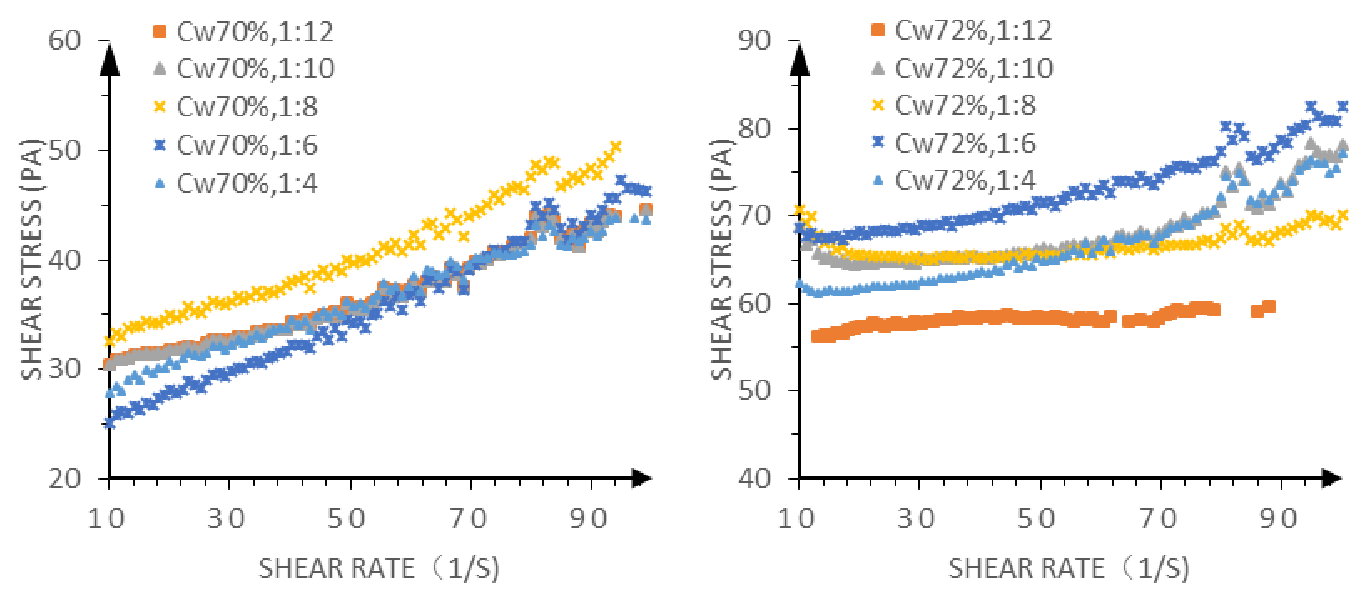

Fig. 7 Rheological behavior curve of filling slurry of the same concentration and different cement-sand ratio

\section{Conclusion}

Through experimental study on mining filling binding materials and adaption of tailings, this paper has reached the following conclusions:

1) Through basis nature examination of mining binding materials, mining cementation powder, except the initial setting time and final setting time, both its $28 \mathrm{~d}$ rupture strength and compressive strength do not reach standard of composite portland cement.

2) Major elements affecting strength of fillings include density of slurry, cement-sand ratio, curing conditions and curing period,etc. By using the SEM to observe the microstructure of fillings, it is found that quantity of gum material in the fillings and its internal compactness is the most important element affecting strength of fillings.

3 ) Through comparative test of the strength of tailing fillings of mining filling binding materials and strength of fillings of cement tailings, it is observed that: the strength of tailing fillings of mining filling cementatious powder is ideal; at the same time, at the same concentration, at the same cement-sand ratio, its strength is higher than that of the tailing fillings of cement. Combining with the basic test results of mining filling binding materials, its matching with mine tailings are superior to cement.

4) Comparative test result of different curing method of fillings indicates that: when the curing period is 28 days, the strength of the whole fillings almost reached its maximum strength; while under the covering curing conditions, 60d strength of fillings increases by small margin; while under the exposure curing conditions, its strength does not increase but also decreases by a small margin; the reason is that the main gel composition AFt in the fillings carbonization has caused reduction of strength.

5) Flow test result shows that: under certain condition of cement-sand ration of filling slurry, its diffusance decreases along with the increase of concentration; under certain concentration, the cement-sand ratio affects fluidity little; through comprehensive analysis, when the concentration of filling slurry is $70 \%$, the fluidity is good, the yield stress that flow of slurry should overcome is smaller than that of slurry when its concentration is $72 \%$. At $72 \%$, gravity feed is difficult.

\section{References}

[1] Xinmin Wang.Filling Theory and Techniques of Deep Mines. [M].Changsha:Central South University Press, 2005: 57-63. (In Chinese) 
[2] Tongyou Liu.Filling Mining Technique and Application[M].Beijing:Metallurgical Industry Press.2003:17-19. (In Chinese)

[3] Mingkai Zhou, Wensheng Zhang, Beixing Li.Study on Property and Hardening Mechanism of High Water Content Solidification Materials[J]. Wuhan University of Technology Journal. 1998: 20(4)18-21. (In Chinese)

[4] Guangming Feng, Yu Ding, Hongjiu Zhu, etc. Mining Ultrahigh Water Filling Materials and Its Structural Experimental Study[J]. China Mining University Journal,2010:39(6)813-817. (In Chinese)

[5] Weidong Ma, Desheng Gu, Jie Wang. High-performance Water-quenched Slag Binding Materials for Filling Mining[J]. Nonferrous Metals,2006:58(1):86-88. (In Chinese) 